\title{
The Ambiguous Effect of Minimum Wages on Hours ${ }^{1}$
}

\author{
Eric Strobl and Frank Walsh* \\ Ecole Polytechnique Paris and University College Dublin
}

\begin{abstract}
In a competitive model we ease the assumption that efficiency units of labour are the product of hours and workers. We show that a minimum wage may either increase or decrease hours per worker and the change will have a sign opposite to that of the slope of the equilibrium hours hourly wage locus. Similarly, total hours worked at a firm may rise or fall. We illustrate the results throughout with a Cobb-Douglas example.
\end{abstract}

Keywords: Minimum wages, hours, employment.

JEL Classification J22, J38

*Corresponding author: Frank Walsh, School of Economics, g216, John Henry Newman building, University College Dublin, Dublin 4 Ireland. Email Frank.Walsh@ucd.ie. Phone: 353-1-7168697.Fax: 353-1-2830068.

\footnotetext{
${ }^{1}$ We are grateful to John Kennan and participants at seminars in U.C.D and Trinity College Dublin for comments.
} 


\section{Section I: Introduction}

The general and long held view amongst economists is that a minimum wage will reduce employment in a competitive labour market. ${ }^{2}$ For example, as Stigler (1946) noted: "The higher the minimum wage, the greater the number of covered workers who are discharged". Importantly, however, this view implicitly assumes a theoretical framework where the labour input can be thought of as total hours and total hours is defined the product of workers and hours per worker. One can arguably though think of a number of different reasons why firms may not take the labour input in the production function as the product of hours and workers. The most basic one is if hours per worker have a diminishing marginal product. Alternatively, firms may have different hours technologies - for example, a long haul trucking company with a couple of large trucks may want a small number of workers with long hours, while a local delivery service may be able to have a large number of workers using the same vehicle. It may also be that differences in the firms demand for the mix of bodies and hours come from the demand conditions facing the firm. For instance, a restaurant in an office district may be very busy for short periods and require a large number of part time workers, while a high street restaurant may be busy over longer periods that facilitate hiring a larger share of full-time workers.

In this paper we thus examine what happens in the standard competitive model when firms are able to choose the number of workers and hours per worker and pay compensating differentials for different levels of hours per worker. Our results show that in such an arguably very plausible setting the impact of minimum wages on hours per worker, the number of workers, and total hours worked is in fact ambiguous. Importantly, the ambiguity of the employment effect in our model does not arise from

\footnotetext{
${ }^{2}$ See Neumark and Wascher (2007) for a survey of the literature on the effect of minimum wages on the labour market.
} 
the inability to pin down substitution effects in a complex model with many heterogeneous factors, but rather comes from applying a minimum wage to a framework that is commonly used in the literature to model how firm's choose combinations of hours and workers in a competitive labour market. We also show that total hours may rise or fall at the industry level when we allow for firm entry and exit.

In contrast to the competitive model, it is of course generally well known that the effect of a minimum wage on employment is not clear in non-competitive models of the labour market. For example, the theoretical possibility that minimum wages may increase employment in a monopsony model was noted as early as Stigler (1946), although he discounted the importance of such models at the time. A more recent literature argues that the Monopsony model is perhaps more relevant in modern labour markets [See Manning (2003)] and Bhaskar and To (1999), Walsh (2003) and Strobl and Walsh (2007), amongst others, present more recent versions of the monopsony model which illustrate the ambiguity of minimum wage employment effects. Also, De Fraja (1999) shows that the employment effects of a minimum wage are small in a model with heterogeneity in workers preferences over wages and working conditions, while Rebitzer and Taylor (1995) demonstrate that minimum wages may increase employment in an efficiency wage model where monitoring becomes more difficult as employment increases. We argue here that regardless of whether one takes a competitive or a non-competitive view of the labour market, the theoretically derived effect of a minimum wage on employment is ambiguous.

One should note that the model we use to demonstrate our argument is based on the notion that firms substitute between hours and workers in response to a minimum wage. However, it could be that the minimum wage graph many of us 
became familiar with as undergraduates - i.e., where hours are fixed and a minimum wage unambiguously leads to some workers being fired in competitive labour markets as firms moved up the labour demand curve - is more appropriate. However, while there are differences across the literature, many empirical studies have rather found substantial movements in hours associated with changes in minimum wages, suggesting that both hours per worker and the number of workers may be affected. More precisely, summarizing the results from the earlier empirical literature on the impact of minimum wages on hours, Brown (1999) concludes that "hours per week fall when minimum wages increase, so the effect on hours worked is more pronounced than the effect on bodies employed" (p. 2156). For instance, Michl (2000) finds a reduction in hours from the widely documented 1990 New Jersey minimum wage increase and argues that this may partly explain conflicting empirical results found by others. Other examples in this regard include Neumark and Schweitzer (2000) or Couch and Wittenberg (2001) who both discover a significant reduction in hours using a panel of U.S states, where the former argue that minimum wage workers are adversely affected by a minimum wage increase. Also, for the UK Stewart and Swaffield (2006) find that the U.K minimum wage reduced hours particularly for males.

Nevertheless, while many of the more recent studies that examine the effect on hours do indeed find a reduction therein, this is not always the case. For example, Katz and Krueger (1992) discover a fall in part-time work for the U.S. Similarly, Zavodney (2000) using a panel of US states finds a fall in the number of workers but increase in hours. Connolly and Gregory (2002) found no effect on hours for women from the national minimum wage in the U.K;. The literature indicates that there is 
there little evidence that hours remain fixed in response to a minimum wage, and that additionally for hours per worker the direction of the impact is not clear-cut. ${ }^{3}$

The remainder of the paper is organised as follows. In the next section we outline our model in a partial equilibrium framework at the firm level. In Section III we discuss market equilibrium in the short run, in section IV. we model firm entry and long run equilibrium and the final section concludes.

\section{Section II: The firm level response to a minimum wage}

The theoretical treatment of minimum wages in the literature when firms choose a combination of hours per worker and workers is rather limited. Hamermesh (1993) develops a model that deals with the firm's choice of workers and hours in a cost minimisation framework (similar to that illustrated in Figure 2 below) which includes a brief discussion of minimum wages, while Michl (2000) outlines a model where firms with a Cobb-Douglas production function over hours and workers choose workers and hours to minimise cost, assuming that the wage does not increase with hours. Other studies, such as Stewart and Swaffield (2006), Zavodney (2000), Neumark and Schweitzer (2000), and Connolly and Gregory (2002) contain some general discussions on how mimimum wages are related to hours but do not build a formal theoretical model.

In this paper we apply a minimum wage to Kinoshita's (1987) model which derives the equilibrium properties of a competitive labour market. In general the equilibrium hours per worker hourly wage locus $h(w)$ [we will refer to this as the hours wage locus from now on] is a set of tangencies where workers who wish to work longer hours match up with like-minded firms. In equilibrium the supply and

\footnotetext{
${ }^{3}$ See Neumark and Wascher (2007) page 40 for details on this literature, as well as an update of the large literature on employment effects on the number of workers and total hours.
} 
demand of each worker type are equal and no worker or firm can gain from deviating to another point on the locus. Compensating wage differentials are paid to workers for working a less desirable number of hours ${ }^{4}$. Firms are assumed to be able to hire as many workers as they wish at any level of hours $(h)$. If there are only a small number of worker types, or one type as in the example we illustrate explicitly, the workers' indifference curve $i s$ the equilibrium hours wage locus. Figure 1 illustrates a tangency between the indifference curve of a representative worker and the isoprofit curve of a firm and is based on the simulation of the Cobb-Douglas example described in Appendix 1. We will use this example throughout the paper to illustrate the results.

It may be worth emphasising that even though firms will choose the wage in the model below, this is not indicative of any market power. Firms are price takers and can hire as many workers as they wish at any given level of hours. In a competitive labour market though, the competitive wage needed to induce different levels of hours will differ and firms can choose any point on the equilibrium hours wage locus.

In this section we assume our model is partial equilibrium in that we ignore the potential impact of the policy on the equilibrium wage hours locus or cost of firm entry. The firm's profit function is:

$$
\Pi(n, w)=p f[n, h(w)]-w n h(w)-k n
$$

where $h$ is hours per worker, $n$ is the number of workers and $q$ is output. Also, there are fixed costs $k$ per worker. The output price $p$ is given to the firm and the production function $q=f(h, n)$ satisfies $f_{n}>0, f_{h}>0, f_{n n}<0 .^{5}$ The firm's choice of $w$ and $n$ at an interior solution satisfies the following first order conditions:

\footnotetext{
${ }^{4}$ The models of Lewis (1969) and Rosen (1986) are the precursors to this model.

${ }^{5}$ If training costs were convex the firm would effectively behave as a monopsonist since worker costs would increase with employment, [see Manning (2003) p34-35].
} 


$$
\begin{aligned}
& \Pi_{w}(n, w)=p f_{h}[n, h(w)] h_{w}(w)-w n h_{w}(w)-n h=0 \\
& \Pi_{n}(n, w)=p f_{n}[n, h(w)]-w h(w)-k=0
\end{aligned}
$$

One can assess the impact of a minimum wage on the number of workers by totally differentiating the first order condition on $n$. Evaluating this differential at the initial equilibrium we get:

$$
\left.\frac{d n}{d w}=-\frac{\Pi_{n w}}{\Pi_{n n}}=\frac{\left[\frac{f_{h}}{n}-f_{n h}\right]}{f_{n n}}\right] h_{w}
$$

Proposition 1: If the scale effect of output on hours per worker is zero the change in the number of workers employed at a firm in response to a minimum wage will have the opposite sign to the slope of the hours wage locus.

Proof:

If the scale effect for hours per worker equals zero we show in Appendix 2 that equation A(1.14) holds with equality implying that $\left.\frac{\left[\frac{f_{h}}{n}-f_{n h}\right]}{f_{n n}}\right]<0$ and that equation (1.3) has the opposite sign to $h_{w}$.

The proposition shows that if the assumption is true a minimum wage will lead to substitution from workers into hours per worker if the wage hours locus is positive and from hours to workers if the slope is negative. We use Figure 2 to illustrate the intuition for the proposition. In contrast to Figure 1 which graphs the isoprofit and indifference curve, Figure 2 depicts the isocost/isoquant graph for an individual firm. ${ }^{6}$ The isocost curve gives the employment hours combinations that are available at a

\footnotetext{
${ }^{6}$ The graphical analysis used here draws on the analysis used in Hamermesh (1993).
} 
fixed level of cost: $C_{0}=w h(w) n+n k$ as defined in Appendix 1 for the Cobb-Douglas example. The isoquant shows the combinations of hours and workers that give a fixed level of output: $H_{o}=H(n, h)$ where $H$ is the aggregate labour input for the Cobb-Douglas function. The initial equilibrium graphed in Figure 2, where the isocost and isoquant are tangent, gives the cost minimising bundle of hours/workers that can produce the desired output. Of course this corresponds to the equilibrium level of hours in Figure 1. When the minimum wage is imposed and the wage hours locus is upward sloping, the firm is forced to pay a higher wage, but can get a higher level of hours per worker in return (as we saw in Figure 1). In Figure 2 the increase in hours implies that at fixed output the firm substitutes from workers into hours moving along the isoquant. Of course the minimum wage will often cause marginal costs and optimal output to change which will in turn affect the demand for workers and hours. We could imagine the isoquant in Figure 2 shifting in response to the minimum wage which would in turn change the demand for workers and hours.

In Proposition One (and indeed for many of the results in the paper) the assumption that scale effects are zero allows us establish sufficient but not necessary conditions for the proposition to hold. Given that the literature modelling firm's choice of workers and hours commonly assumes that scale effects are zero ${ }^{7}$ and that as we discuss below positive or negative scale effects have unusual implications in this model and can be difficult to interpret we argue that focussing on the case where scale effects are zero is a reasonable restriction especially since we use the assumption to establish sufficient conditions for our results to hold. That is even when we impose this assumption the results will still hold in some cases where scale

${ }^{6}$ For example Cahuc and Zylberberg (2001) use a technology with this assumption while Hamermesh (1993) discusses this literature and the functional forms used. 
effects are positive or negative. From (1.3) and the production function we see that the change in firm output from a minimum wage is:

$$
\frac{d f}{d w}=f_{n} \frac{d n}{d w}+f_{h} \frac{d h}{d w}=\left[f_{n}\left(\frac{\frac{f_{h}}{n}-f_{n h}}{f_{n n}}\right)+f_{h}\right] h_{w}
$$

In equation $\mathrm{A}(1.17)$ in Appendix 2 we show that the term in square brackets in (1.4) will be positive/negative if hours per worker is inferior/not inferior ${ }^{8}$. This implies for example that if the wage hours locus has a positive sign the change in marginal costs from imposing a minimum wage will be non-positive unless hours are an inferior input. It is also worth emphasizing that in the more standard case where a firm has two inputs with separate prices (say a firm using capital and labour) the condition for an input to be inferior is a good deal more stringent than here. For example a necessary condition for a factor to be inferior in this more standard case is that the cross partial derivative between the inputs in the production function must be negative [see Bear (1965)] ${ }^{9}$. To illustrate this point further we could take a commonly used functional form such as the constant elasticity of substitution function for the labour aggregator. In this case hours will be inferior/not inferior if the elasticity of substitution between hours and workers is greater/less than unity ${ }^{10}$. Of course in the standard case of two inputs with two prices neither input would be inferior if we use the C.E.S. production function. In addition it has been noted in the literature that the

\footnotetext{
${ }^{8}$ We also show show in Appendix 2 that a minimum wage lowers marginal cost in this case. Because the minimum wage is imposed just above the optimal wage, the change in average costs and profits will approach zero.

${ }^{9}$ Another interesting distinction is that Bear shows that an increase in the price of an inferior input lowers marginal costs for the standard case, where we see above that for the labour aggregator with hours depending on the hourly wage marginal costs only decrease if the wage hours locus has a negative slope.

${ }^{10}$ That is if the labour aggregator is $f(n, h)=\left[z+\alpha h^{\delta}+\beta n^{\delta}\right]^{\frac{1}{\delta}}$ where $z, \alpha, \beta$ and $\delta$ are positive constants and the elasticity of substitution $\sigma=\frac{1}{1-\delta}$ is positive so that $-\infty<\delta<1$. The Cobb-Douglas case is $\delta=0$.
} 
intuition for hours increasing or decreasing systematically with the scale of production is not clear. For example Hamermesh (1993) argues, that “...there is no evidence that weekly hours of full-time workers at General Motors differ substantially from hours of workers at the local steel fabricator'(p.50).

What may be puzzling with regard to Proposition 1 is that much of the existing empirical evidence discussed earlier suggests a decline in hours per worker from a minimum wage. ${ }^{11}$ This would suggests from this proposition that affected firms that decrease hours should increase the number of workers, but would also imply that workers are on a negatively sloped hours wage locus. There is no reason that this should not be so in theory, but one may suspect that many economists would expect the contrary. For example, Hamermesh (1993) assumes the equilibrium locus has a positive slope in his treatment of the theory of hours per workers, while Michl (2000) supposes the locus is flat. Interestingly, in a monopsony model where the supply of workers to the firm depends on the utility of the hours wage combination offered by the firm, a fall in hours in response to a minimum wage does not imply a downward sloping hours wage locus [see Strobl and Walsh (2007) for example $]^{12}$. That is, if one wishes to reconcile reductions in hours per worker with an upward sloping wage hours locus which violates Proposition 1, non-competitive models can easily do this. This apart, the proposition should certainly make one reluctant to conclude that one can infer whether the labour market is competitive or not by looking at the results of studies that focus on the number of workers, as some of the literature does, since

\footnotetext{
${ }^{11}$ For instance, Neumark and Wascher (2007) note "..although much of the literature has focused on the employment effects of the minimum wage, the predictions of theory tend to be about overall labour input rather than employment specifically.. (p.166)".

12 This conclusion may not be immediately obvious from reading Strobl and Walsh (2007) but it is straightforward to show using the model simulated in that paper that there is a range of parameters where the wage hours locus is positively sloped but a minimum wage reduces hours. The range where this is true expands with the degree of monopsony power. A maple file containing this simulated model is available from the authors.
} 
theory has no clear prediction on the change in hours per worker and predicts an offsetting change in the number of workers.

We next examine the conditions under which a minimum wage will increase total hours. In this regard we define the elasticity of output with respect to workers (n) and hours per worker $(h)$, respectively, as $f_{h} \frac{h}{f}=\varepsilon_{q h}$ and $f_{n} \frac{n}{f}=\varepsilon_{q n}$. It follows from the first order conditions (1.2) that:

$$
h_{w}=\frac{h}{w}\left[\frac{1}{\left(1+\frac{k}{w h}\right) \frac{\varepsilon_{q h}}{\varepsilon_{q n}}-1}\right]
$$

If one thinks of employment as total hours $(n h)$, then using (1.4) and (1.5) the employment effect would be:

$$
\frac{d(n h)}{d w}=n \frac{d h}{d w}+h \frac{d n}{d w}=n\left[1+\frac{h}{n}\left(\frac{\frac{f_{h}}{n}-f_{n h}}{f_{n n}}\right)\right] h_{w}
$$

But using (1.5) this can be written as:

$$
\varepsilon_{n h, w}=\frac{d(n h)}{d w} \frac{w}{n h}=\frac{1+\frac{h}{n}\left(\frac{\frac{f_{h}}{n}-f_{n h}}{f_{n n}}\right)}{\left(1+\frac{k}{w h}\right) \frac{\varepsilon_{q h}}{\varepsilon_{q n}}-1}
$$

Next we assume that hours per worker is not an inferior input. That is, hours per worker does not fall as output increases, other things equal $\left[\frac{d h}{d q} \geq 0\right.$ for the production function $q=f(n, h)]$. We show in Appendix 2 that if this assumption holds and marginal costs are positive then:

$$
-\frac{f_{h}}{f_{n}} \leq \frac{\left(\frac{f_{h}}{n}-f_{h n}\right)}{f_{n n}}
$$


For expositional purposes we will use (1.3) to define $\frac{\frac{f_{h}}{n}-f_{n h}}{f_{n n}}=-\frac{f_{h}}{f_{n}}+x$ where $x \geq 0$ from (1.3). In the special case where the scale effect on hours equals zero $x$ also equals zero. Using this definition we rewrite (1.7):

$$
\varepsilon_{n h, w}=\left[\frac{1+\frac{h}{n} x-\frac{\varepsilon_{q h}}{\varepsilon_{q n}}}{\left(1+\frac{k}{w h}\right) \frac{\varepsilon_{q h}}{\varepsilon_{q n}}-1}\right]
$$

The condition for the numerator and denominator of (1.9) to be positive, where it follows that the elasticity of total hours with respect to a minimum wage is positive, is:

$$
\frac{1}{1+\frac{k}{w h}}<\frac{\varepsilon_{q, h}}{\varepsilon_{q, n}}<1+x \frac{h}{n}
$$

A feature of this result is that one does not need extreme values for the elasticities of output with respect to workers and hours for the impact on total hours to be positive. For example, when the elasticity of output with respect to workers exceeds the elasticity of output with respect to hours $\left(\varepsilon_{q n}>\varepsilon_{q h}\right)$, but these elasticities are similar, the presence of small fixed costs or small scale effects on hours will ensure a positive effect even if scale effects are zero. If there are positive scale effects the result may hold without positive fixed costs.

Another way of illustrating the cases where total hours may increase is by establishing the following proposition.

Proposition 2: If $\varepsilon_{q n}>\varepsilon_{q h}$ a minimum wage will increase total hours worked if the hours per worker, hourly wage locus has a positive slope. 
Proof: From (1.5) if the hourly wage locus has a positive slope the denominator of (1.9) is positive. But since $x, h$ and $n$ are positive if $\varepsilon_{q n}>\varepsilon_{q h}$ the numerator of (1.8) is positive implying $\varepsilon_{n h, w}>0$.

This implies that if some of the combinations of assumptions often made in this literature hold, then total hours will increase. As noted earlier, it is common to assume that the wage hours locus has a positive slope, while Feldstein (1967) and Michl (2000) amongst others explicitly assume $\varepsilon_{q n}>\varepsilon_{q h}$. We do not wish to argue based on Proposition 2 that one should typically expect total hours to increase. Rather it is to show that when one uses the type of simple competitive models that are used to establish the intuition that minimum wages lower employment, modifying the model using the standard approaches that have been used to analyse how a firm combines workers and hours, the result becomes ambiguous. This is so for parameter assumptions that have been commonly made in the hours/worker literature.

\section{Section III: Market Equilibrium}

Section II analyses the response to a minimum wage of a firm in a general competitive model for given market conditions (i.e., a given hours wage locus). Of course it may well be that the equilibrium hours wage locus is affected by the minimum wage, but it would be very difficult to explicitly solve for market equilibrium in a model with many worker and firm types. For this reason we focus on a simple model with a representative firm and assume that workers are identical except for a fixed disutility from going to work. Imposing these assumptions limits the degree of heterogeneity across workers and firms and means that we ignore any 
potential spillover effects across different types of workers and firms resulting from the policy change. However, since the main conclusion of the paper is that employment effects are ambiguous, our contention is that it is unlikely that generalising the model to include greater heterogeneity across workers and firms would lead to an unambiguous result.

To solve fully for the impact of the minimum wage on the market equilibrium we must make assumptions about the supply of workers and firm entry on the demand side. We will ignore firm entry until we come to the next section. We can think of the analysis in this section as focusing on short run market equilibrium.

We might expect that at the level of the market the number of workers willing to supply labour would slope upwards with respect to worker utility. To take account of this in a tractable way we proceed as follows: We assume that workers satisfy the constraints $h=(T-l)$, where $h$ is hours worked and $T$ is a time endowment which is common to all workers and $l$ is leisure. Consumption expenditure is $x$ (where workers satisfy the budget constraint $w h=x$ ). Utility is increasing in consumption and leisure and substituting for the above constraints one gets the utility function $u[d(h, w), v]$, which we assume is weakly separable in $v .^{13}$ We assume that the utility function is monotonically decreasing in the parameter $v$ which is distributed over a mass $M$ of workers according to the function $G(v)$. All workers have reservation utility $S$. These assumptions ensure that at any equilibrium hours wage bundle $\left(w^{*}, h^{*}\right)$ workers with low enough values of $v$ such that their utility at $d(h, w)$ exceeds the reservation level $S$ will supply labour. This framework means that for the number of workers willing to supply labour to increase $v$ will be higher for the marginal worker, so that $d(h, w)$ must also increase. The marginal worker gets utility of exactly $S$. Weak separability

\footnotetext{
${ }^{13}$ This model of labour supply is based on Strobl and Walsh (2007).
} 
of $v$ ensures that each worker that supplies labour is on the same indifference curve over hours and wages, which is just the indifference curve of the marginal worker. Since this indifference curve gives the rate at which each worker trades off hourly wages and hours, it is the equilibrium hours wage locus which each firm takes as given. The reason we need to model this is that if a policy such as a minimum wage were to lead to an equilibrium with a higher number of workers, this implies that the marginal worker would have a higher value of $v$. The indifference curve of this worker would now be the equilibrium hours wage locus. That is, the policy may shift the equilibrium locus and we must take account of this shift. The equilibrium value of $v^{*}$ ensures that:

$$
u\left[d(h, w), v^{*}\right]=S
$$

That is $v^{*}(h, w)$ is the value of $v$ for the marginal worker who is just willing to supply labour. We can map from the equilibrium value of $v^{*}$ to get labour supply:

$$
N^{s}(h, w)=M G\left[v^{*}\right]
$$

Also from (1.10) once we know $v^{*}$ we can solve for the equilibrium hours locus that the firms face, which is just the indifference curve of the marginal worker. The equilibrium level of utility/profit is determined where labour supply equals labour demand:

$$
N^{d}(h, w)=n^{d}\left[h\left(w, v^{*}\right)\right] F
$$

The number of firms which is fixed in the short run is $F$ and the demand for workers at each firm is $n^{d}[w(h)]$. Equations (1.12) and (1.13) will be equalised in market equilibrium. This is illustrated in Figure 3 for the Cobb-Douglas example outlined in 
Appendix $1^{14}$. We see there is downward sloping inverse demand curve and upward sloping inverse supply curve in $v$ worker space.

To get the change in the demand for workers after a minimum wage we totally differentiate the first order condition on workers from equation (1.2):

$$
d \Pi_{n}=p f_{n n} d n^{d}+\left[p f_{n h} h_{w}-w h_{w}-h\right] d w+\left[p f_{n h}-w\right] h_{v} d v=0
$$

The first two terms in (1.13) correspond to the total derivative from the firm's problem used to derive equation (1.4). Equation (1.14) has an additional term reflecting the fact that the minimum wage can change the market hours wage locus by changing $v$. Using the first order condition on hours in (1.13) we get the change in the demand for workers resulting from a minimum wage as:

$$
\frac{d N^{d}}{d w}=F \frac{d n^{d}}{d w}=F\left(n_{w}^{d}+n_{d}^{v} v_{w}\right)=F\left\{\left[\frac{\frac{f_{h}}{n}-f_{n h}}{f_{n n}}\right] h_{w}+\frac{\left[w-p f_{n h}\right]}{p f_{n n}} h_{v} v_{w}\right\}
$$

Before proceeding it will be useful to establish that when a minimum wage is introduced $h_{w}$ and $h_{v}$ will have the opposite signs. Using the fact that equation (1.11) will continue to hold we see that $\left.\frac{d u\left[D(h, w), v^{*}\right]}{d v^{*}}\right|_{w=w}=\frac{\partial u}{\partial D} \frac{\partial D}{\partial h} \frac{\partial h}{\partial v^{*}}+\frac{\partial u}{\partial v^{*}}=0$. Since $\frac{\partial u}{\partial D}>0, \frac{\partial u}{\partial v^{*}}<0$ then $\frac{\partial D}{\partial h}$ and $\frac{\partial h}{\partial v^{*}}$ must have the same sign to ensure that this equation equals zero. But $\frac{\partial D}{\partial h}$ has the opposite sign to $\frac{\partial h}{\partial w}$. To illustrate this imagine that the indifference curve in Figure 1 is the equilibrium hours wage locus. An increase in $h$ when the wage is held fixed at any point puts the workers on a higher indifference curve when the indifference curve has a negative slope and on a lower indifference curve when the indifference curve has a positive slope.

\footnotetext{
${ }^{14}$ Figure 3 also includes the long run demand curve which will be modelled in the next section.
} 
The change in the supply of workers is:

$$
\frac{d N^{s}(h, w)}{d w}=M G_{v} v_{w}
$$

From (1.15) and (1.16) we see that if the market moves to a new quilibrium after the minimum wage we should have $F\left(n_{w}^{d}+n_{v}^{d} v_{v}\right)=M G_{v} v_{w}$. While $n_{w}^{d}$ has the opposite sign to the hours wage locus from proposition one we will see that in many cases and indeed for the Cobb-Douglas case we analyse explicitly $n_{v}^{d}$ will have the opposite sign to $n_{w}^{d}$. This means that even though the equilibrium relationship between labour demand and $v$ is negative as we saw in Figure 3 this relationship will often be positive after a minimum wage. An unconstrained firm will respond to an increase in $v$ by adjusting the wage hours combination. However if there is a minimum wage a firm cannot adjust the wage and the entire adjustment is in hours. Imagine firms are on a positive wage hours locus and a minimum wage is enforced. From proposition one firms lay-off workers causing a decrease in $v$, the decrease in $v$ induces firms to increase hours further if the wage hours locus is positive since as we saw above $h_{w}$ and $h_{v}$ have opposite signs under a minimum wage. The increase in hours may induce firms to lay-off more workers. Even if this is so the market will return to equilibrium as long as the slope of the inverse labour supply curve $M G_{v}$ (which is positive by assumption) is greater than the slope of the restricted inverse labour demand where the wage is fixed. Figure 4 illustrates $F n_{v}^{d}$ and $M G_{v}$ for the CobbDouglas case we analyse in the Appendix. We see that since the inverse labour demand curve is flatter than the labour supply curve in this graph, the market will return to equilibrium for our Cobb-Douglas example after a minimum wage and the fall in the number of workers after a minimum wage will be greater than the initial 
response by firms. If $M G_{v}-n_{v}^{d}<0$ however the labour market will diverge from the initial equilibrium after a minimum wage is imposed. We will focus on the case where the market reurns to equilibrium. We set (1.15) equal to (1.16) and solve for the equilibrium change in $v^{*}$ :

$$
v_{w}=\frac{F\left[\frac{\frac{f_{h}}{n}-f_{n h}}{f_{n n}}\right] h_{w}}{M G_{v}-F \frac{\left[w-p f_{n h}\right]}{p f_{n n}} h_{v}}
$$

We can insert this in (1.15) or (1.16) to get the equilibrium change in employment:

$$
\begin{aligned}
& \frac{d N^{d}}{d w}=F\left(n_{w}+n_{v} v_{w}\right)=F\left[\frac{\frac{f_{h}}{n}-f_{n h}}{f_{n n}}\right] h_{w}\left\{\frac{M G_{v}}{M G_{v}-F \frac{\left[w-p f_{n h}\right]}{p f_{n n}} h_{v}}\right\} \\
& =F\left[\frac{\frac{f_{h}}{n}-f_{n h}}{f_{n n}}\right] h_{w} Y
\end{aligned}
$$

Proposition 1(a): A sufficient condition for Proposition one to continue to hold for the aggregate number of workers in short run market equilibrium is that the firms inverse demand curve in worker $v$ space is flatter than the market supply curve after a minimum wage is imposed.

Proof: The slope of the inverse supply curve is $M G_{v}$ while the slope of the inverse demand curve is $F \frac{\left[w-p f_{n h}\right]}{p f_{n n}} h_{v}$. If $M G_{v}-F \frac{\left[w-p f_{n h}\right]}{p f_{n n}} h_{v}>0$ then $Y>0$ and Proposition one holds since (1.18) is just (1.3) times a positive constant.

Next we analyse the short run change in total hours worked at the market level. We note that from the firm's first order conditions (1.6) will continue to hold. Using (1.6) and (1.17) we can write the change in total hours at a firm as: 


$$
\begin{aligned}
& \frac{d(N h)}{d w}=N\left(h_{w}+h_{v} v_{w}\right)+h \frac{d N}{d w}= \\
& =\left[1+\frac{h}{n}\left(\frac{\frac{f_{h}}{n}-f_{n h}}{f_{n n}}\right)\left(1+\frac{G}{G_{v} v} \frac{h_{v} v}{h} \frac{F n}{M G}\right) Y\right] N h_{w}
\end{aligned}
$$

Using (1.5) the value of $h_{w}$ from the firms first order conditions and using the equation $\frac{\frac{f_{h}}{n}-f_{n h}}{f_{n n}}=-\frac{f_{h}}{f_{n}}+x$ as we did in (1.8). We also note that since we start at labour market equilibrium $\frac{F n}{M G}=1$.

we can calculate the elasticity of total hours with respect to the wage in this case as:

$$
\varepsilon_{n h, w}=\left[\frac{1+\left(\frac{h}{n} x-\frac{\varepsilon_{q h}}{\varepsilon_{q n}}\right)\left(1+\frac{G}{G_{v} v} \frac{h_{v} v}{h}\right) Y}{\left(1+\frac{k}{w h}\right) \frac{\varepsilon_{q h}}{\varepsilon_{q n}}-1}\right]
$$

Using the value for Y we can also write:

$$
\left(1+\frac{G}{G_{v} v} \frac{h_{v} v}{h}\right) Y=\left\{\frac{M G_{v}+\frac{M G}{h} h_{v}}{M G_{v}-F \frac{\left[w-p f_{n h}\right]}{p f_{n n}} h_{v}}\right\}
$$

Proposition 2(a): Proposition two continues to hold for total market hours worked in short run market equilibrium if the firm's inverse demand curve in worker $v$ space is flatter than the market supply curve after a minimum wage is imposed.

Proof: We note that Proposition 2 is concerned with the case where $h_{w}>0$. In the discussion preceeding Proposition 1(a) we saw that $h_{v}<0$ in this case. If we can 
show that equation (1.21) the elasticity of total hours under short run equilibrium is greater than equation (1.9) the elasticity of total hours at the firm level, then the proposition continues to hold. Using equation (1.22) in (1.21) and comparing with (1.9) when $h_{w}>0$ we see that the proposition will certainly hold if the expression in (1.22) is less than or equal to unity and in particular $\frac{M G}{h} \geq-F \frac{\left[w-p f_{n h}\right]}{p f_{n n}}$ since $h_{v}<0$ and $M G_{v}-F \frac{\left[w-p f_{n h}\right]}{p f_{n n}} h_{v}>0$ by assumption. Using the first order condition on $h$ and the market equilibrium condition this inequality can be rewritten as:

$$
\begin{aligned}
& \frac{M G}{F n}=1 \geq \frac{h}{n}\left(\frac{f_{n h}-\frac{f_{h}}{n}}{f_{n n}}\right)+\frac{h}{n} \frac{h}{p f_{n n} h_{w}} \\
& =\frac{f_{h}}{f_{n}} \frac{h}{n}-x \frac{h}{n}+\frac{h}{n} \frac{h}{p f_{n n} h_{w}}
\end{aligned}
$$

Since $-x \frac{h}{n}<0$ and $\frac{h}{n} \frac{h}{p f_{n n} h_{w}}<0$ when $h_{w}>0$ we see immediately that the inequality in (1.23) will hold if $\frac{f_{h}}{f_{n}} \frac{h}{n}=\frac{\varepsilon_{q, h}}{\varepsilon_{q, n}}<1$. But $\varepsilon_{q, n}>\varepsilon_{q, h}$ is one of the assumptions in Proposition 2.

\section{Section IV: Firm entry}

In this section we extend the analysis in section III to allow for the fact that in the long run a minimum wage may affect firms profits and in turn the number of firms. It may seem reasonable to assume that when we examine the introduction of a minimum wage close to the equilibrium wage, the impact of profits will be small. In a competitive model where hours are held fixed this would be a reasonable supposition. After a minimum wage firms could find as many workers as they need. 
Wages would be slightly higher but the impact on profits would be small as long as firms had been optimising and the minimum wage is small. This is no longer the case when we allow hours to vary. The minimum wage causes substitution between hours and workers. If the supply of workers is positively related to worker utility, the effect of each firm attempting to hire more/less workers in response to a minimum wage will be to cause the hours wage locus to shift up/down as we saw in the previous section. This shift in the equilibrium hours wage locus will indeed have a first order effect on profits. ${ }^{15}$ We will assume that there is free entry of firms but the fixed cost of firm entry is driven up as the number of firms $F$ increases. In equilibrium the number of firms will be such that the fixed entry cost $E(F)$ equals firm profits and so the mass of firms is increasing as profits increase. The minimum wage affects firm profits by shifting the hours wage locus through the parameter $v$. We can write:

$$
n \frac{d F}{d w}=n \frac{d F}{d \Pi} \frac{d \Pi}{d v} \frac{d v}{d w}
$$

Totally differentiating the profit function we note that since we impose a small minimum wage starting at the optimum the first order conditions for the firm (1.2) will continue to hold so that $\Pi_{n}=\Pi_{w}=0$ and from the total derivative of the profit function: $\frac{d \Pi}{d v} \frac{d v}{d w}=\left(p f_{h}-w n\right) h_{v} \frac{d v}{d w}$. From the first order condition on $w$ we can say that $\left(p f_{h}-w n\right)=\frac{h n}{h_{w}}$. Using both of these equations we get the change in profits from a minimum wage:

$$
\frac{d \Pi}{d v} \frac{d v}{d w}=h n \frac{h_{v}}{h_{w}} \frac{d v}{d w}
$$

\footnotetext{
${ }^{15}$ Bhaskar and To (1999) show in a monopsony model that while the immediate impact of a small minimum wage on the profits of an optimising firm will be second order, there is a first order negative impact on profits since the firms labour supply curve depends not only on its own wage but on the relative wage of other firms which increase.
} 
We proceed to incorporate the impact on profits into the analysis of section III. The expression for $\frac{d n}{d w}$ is derived in the same way as (1.15). We also account for firm entry using (1.25):

$$
\frac{d N^{d}}{d w}=F \frac{d n}{d w}+n \frac{d F}{d w}=F\left[\frac{\frac{f_{h}}{n}-f_{n h}}{f_{n n}}\right] h_{w}+\left\{F\left[\frac{w-p f_{n h}}{p f_{n n}}\right] h_{v}+n h n \frac{h_{v}}{h_{w}} \frac{d F}{d \Pi}\right\} v_{w}
$$

Supply and demand for workers will be equal in equilibrium so that one can equate (1.26) with the derivative of the supply of workers (1.16) to get:

$$
v_{w}=\frac{\left.\frac{\frac{f_{h}}{n}-f_{n h}}{f_{n n}}\right] h_{w}}{M G_{v}-\left\{F\left[\frac{w-p f_{n h}}{p f_{n n}}\right] h_{v}+n h n \frac{h_{v}}{h_{w}} \frac{d F}{d \Pi}\right\}}
$$

This in turn can be substituted back into (1.26) to get the change in equilibrium employment:

$$
\begin{aligned}
& \frac{d N^{d}}{d w}=F\left[\frac{\frac{f_{h}}{n}-f_{n h}}{f_{n n}}\right] h_{w}\left[\frac{M G_{v}}{M G_{v}-\left\{F \frac{\left[w-p f_{n h}\right]}{p f_{n n}} h_{v}+n h n \frac{h_{v}}{h_{w}} \frac{d F}{d \Pi}\right\}}\right] \\
& =F\left[\frac{\frac{f_{h}}{n}-f_{n h}}{f_{n n}}\right] h_{w} Y 1
\end{aligned}
$$

Proposition 1(b): A sufficient condition for Proposition 1(a) to continue to hold in long run market equilibrium is that the firms inverse demand curve in worker $v$ space is flatter than the market supply curve after a minimum wage is imposed.

Proof: The slope of the inverse market supply curve is $M G_{v}$ and the slope of the inverse market demand curve after a minimum wage is imposed is $F \frac{\left[w-p f_{n h}\right]}{p f_{n n}} h_{v}+n h n \frac{h_{v}}{h_{w}} \frac{d F}{d \Pi}$. If the slope of the inverse supply curve is larger $Y 1>0$ and comparing with equation (1.3) we see that Proposition 1 will continue to hold. 
We note that the firm entry term in (1.28) reduces the slope of the inverse demand curve in $\mathrm{v}$ worker space. That is the proposition is more likely to hold in long run equilibrium than in short run equilibrium.

We can also now establish the following proposition:

Proposition 3: If Proposition 1(b) holds the change in the long run equilibrium level of firm profits resulting from a minimum wage will have the same sign as the slope of the hours wage locus.

Proof: If Proposition 1(b) holds Y1>0 and from (1.27) $\frac{d v}{d w}$ has the opposite sign to $h_{w}$. Equation (1.25) gives us the change in profits from a minimum wage $\frac{d \Pi}{d v} \frac{d v}{d w}=h n \frac{h_{v}}{h_{w}} \frac{d v}{d w}$. Since $h_{v}$ and $h_{w}$ have opposite signs the change in profits will have the same sign as the slope of the hours wage locus.

This is a surprising result implying for example that when the hours wage locus has a positive slope, a minimum wage will increase firm profits. The result makes intuitive sense given the framework we have adopted. If the hours wage locus has a positive slope a minimum wage causes the firm to substitute from hours into workers. If the firm is starting at the optimum any negative impact of this change on profits will be small. However as all firms substitute from hours to workers, the demand for workers falls and the equilibrium hours locus shifts down which causes a first order increase in firm profits. Given the amount of structure in this simple model and that we do not typically find low skill workers campaigning against minimum wages or low skill employers campaigning for them, we do not want to make too 
much of this result ${ }^{16}$. We see the proposition as supporting the general point that we should be slow to assume that the theoretical predictions of the impact of a minimum wage in a competitive model are clear.

Equation (1.28) allows us calculate the impact of the change in profits from a minimum wage on firm entry and total hours worked in long run equilibrium is derived in the same way as (1.20):

$$
\begin{aligned}
& \frac{d(N h)}{d w}=N\left(h_{w}+h_{v} v_{w}\right)+h \frac{d N}{d w}= \\
& =\left[1+\frac{h}{n}\left(\frac{\frac{f_{h}}{n}-f_{n h}}{f_{n n}}\right)\left(1+\frac{G}{G_{v} v} \frac{h_{v} v}{h}\right) Y 1\right] N h_{w}
\end{aligned}
$$

Proposition 2(b): Proposition two continues to hold for total market hours worked in short run market equilibrium if the firm's inverse demand curve in worker $v$ space is flatter than the market supply curve after a minimum wage is imposed. Proof: since $Y 1>Y$ the proposition follows in the same way as Proposition 2(a)

It may be useful to illustrate these results in a familiar example. In the long run equilibrium section of Appendix 1 we assume a linear relationship between firm entry and the level of profit and additionally assume that the weight on workers $b$ equals one minus $a$ the weight on hours. Assuming parameter values in Figure 3 we graph the elasticity of total hours worked in long run market equilibrium with respect to minimum wage -equation (1.26) weighted by the wage and total hours - and also the elasticity of total hours when we look at the firms initial response to the minimum

\footnotetext{
${ }^{16}$ Neumark and Schweitzer (2000) present a model where minimum wages may lower worker utility.
} 
wage - equation (1.7) weighted by the number of firms. The solutions to the firms problem are well behaved for all the parameter values in the graph ${ }^{17}$. One can see that when the weight on workers and firms in the production function are similar in that the presence of fixed costs creates a range of parameter values where total hours increases as we demonstrated earlier. The propositions establishing that total hours increase are based on sufficient conditions and we see in fact that for long run equilibrium total hours in Figure 3 there is a wider range of parameter values where total hours increase compared to the elasticity of hours when we look at the firms initial response to the minimum wage.

\section{Section IV: Conclusion}

The idea that minimum wages may lead to offsetting effects on hours per worker is generally recognised in the literature. However, given the prevalence of studies that focus solely on the number of workers, we suspect that the fact that changes in hours per workers and the number of workers from a minimum wage can be either positive or negative and that theory predicts that the two will typically be inversely related in a competitive labour market is not yet well understood.

While we show that there are cases where firms may respond to a minimum wage by increasing total hours, we are not suggesting that one should necessarily expect this to be typically true. Having said this, the parameter values where total hours effects are positive are not implausible (the effect may be positive for small fixed effects if the elasticity of output with respect to hours and workers are similar in the production function). It may well be that different firms in different sectors with different technologies could be affected very differently by a minimum wage. This

\footnotetext{
${ }^{17}$ A maple file generating the graphs and showing that the firms second order conditions are satisfied and that profits hours workers the number of firms etc. are all positive for all the examples given is available from the authors on request.
} 
means that while empirical analysis that focuses on a homogeneous group of low skilled workers (say in the fast food industry) will resolve a lot of estimation problems and may provide compelling results for that group of workers, the theoretical analysis implies that even if labour markets are competitive the results may not be representative of the impact of a minimum wage across all industries.

We also showed that a firm may increase total hours after a minimum wage and yet workers may have lower utility in equilibrium. Since one could reasonably argue that the participation rate of workers is positively related to the utility of jobs on offer, then if one wishes to test whether minimum wages increase or decrease worker utility in a model with offsets, a simple route might be to determine whether aggregate employment has increased. More precisely, if more workers are attracted to working in the labour market then utility must be higher in order to attract these workers. At a market level therefore, we can plausibly argue that if total employment rises in response to a minimum wage then worker utility is increasing. 


\section{References}

Bear, D. V. T. (1965) "Inferior inputs and the Theory of the Firm" The Journal of political Economy, Vol.73. No. 3, June, pp. 287-289.

Bhaskar, V., and To, T. (1999) 'Minimum Wages for Ronald McDonald Monopsonies: A Theory of Monopsonistic Competition'. Economic Journal, Vol. 109 (April), pp.190-203.

Blundell, Richard and Thomas Macurdy, (1999) "Labor Supply: A Review of Alternative Approaches" in the Handbook of Labor Economics, Vol. 3A, chapter 27. Edited by Orley Ashenfelter and David Card, Elsevier Press.

Brown Charles (1999) "Minimum Wages,Employment, and the Distribution of Income" Handbook of Labor Economics Volume 3B. Edited by Orley Ashenfelter and David Card.

Card, David and Alan Krueger (1995), Myth and Measurement: the New Economics of the Minimum Wage. Princeton: Princeton University Press.

Connolly, Sarah and Mary Gregory (2002)"The National Minimum Wage and Hours of Work: Implications for Low Paid Women" Oxford Bulletin of Economics and Statistics December

John DiNardo, Nicole M. Fortin and Thomas Lemieux (1996) Labor Market Institutions and the Distribution of Wages, 1973-1992: A Semiparametric Approach Econometrica, Vol. 64, No. 5., pp. 1001-1044.

De Fraja, G. (1999). "Minimum Wage Legislation, Productivity and Employment", Economica, 66, pp. 473-88.

Dickens, Richard and Alan Manning (2004) "Spikes and Spillovers: the Impact of the National Minimum Wage on the Wage Distribution in a Low wage Sector" Economic Journal, March c95-101

Feldstein, M.S. (1967) "Specification of the Labour Input in the Aggregate production Function”, Review of Economic studies, Vol. 34, October, 375-386.

Hamermesh, Daniel, (1993) Labor Demand. Princeton University Press.

Katz, Lawrence F. and Alan B. Krueger (1992) "The Effect of the Minimum Wage on the Fast-Food Industry" Industrial and Labor relations Review, Vol. 46, No. 1, 6-21.

Kinoshita, Tomio, (1987) "Working Hours and Hedonic Wages in the Market Equilibrium." Journal of Political Economy, Vol. 95, no. 61 pp. 1262-1277

Lewis, H.G. (1969) "Interes del Empleador en las Horas de Trabajo del Empleado" Cuadernos de Economia, 18, pp38-54 
Manning, A. (2003). "Monopsony in Motion, Imperfect Competition in Labor Markets" Princeton University Press

Michl, Thomas R. (2000), "Can rescheduling explain the New Jersey minimum wage studies?” Eastern Economic Journal, 26, 265-276.

Neumark, David and William L. Wascher (2007) "Minimum Wage and Employment" Foundations and trends in Microeconomics, Vol. 3, No. 1-2 pp1-182.

Neumark, David and Mark Schweitzer and (2000) "The Effects of Minimum wages Throughout the Wage Distribution,” NBER Working Paper \#7519

Rebitzer, James and Lowell Taylor (1995) "The Consequences of Minimum Wage Laws: Some new Theoretical Ideas" Journal of Public Economics 56 245-255

Rosen, Sherwin (1986) "The Theory of Equalizing Differences" in The Handbook of Labor Economics Volume 1 part 2 Chapter 12.

Stewart, Mark B. and Joanna K. Swaffield (2006) " The other margin: do minimum wages cause working hours adjustments for low-wage workers?" Economica, Forthcoming

Stigler, G. 1946. The economics of minimum wage legislation. American Economic Review 36: 358-365.

Strobl, Eric and Frank Walsh (2007) "Dealing with monopsony power: Employment subsidies vs. minimum wages.”, Economics Letters, 94, pp. 83-89.

Walsh, F. (2003). Comment on minimum wages for Ronald McDonald monopsonies: Atheory of monopsonistic competition. Economic Journal. 113: 718-722

Zavodney, Madline, (2000) "The effects of the Minimum wage on Hours of Work" Labour Economics, Vol. 7, pp. 729-750 
Figure 1: equilibrium wages and hours

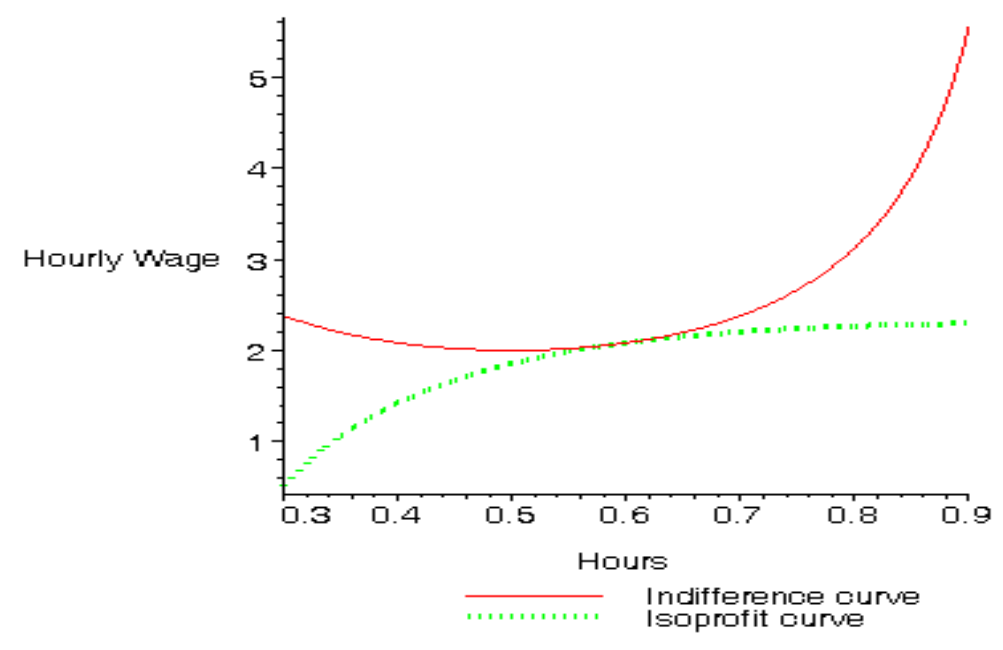

Figure 2: The cost minimising bundle of hours/workers

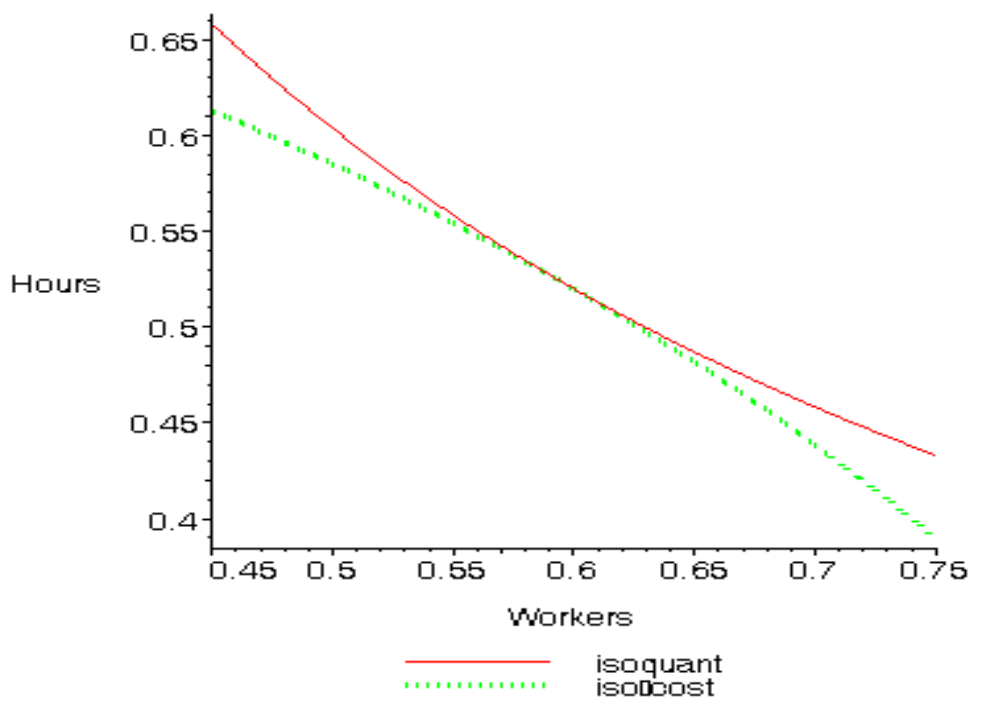


Figure 3: Short and long run market equilibrium

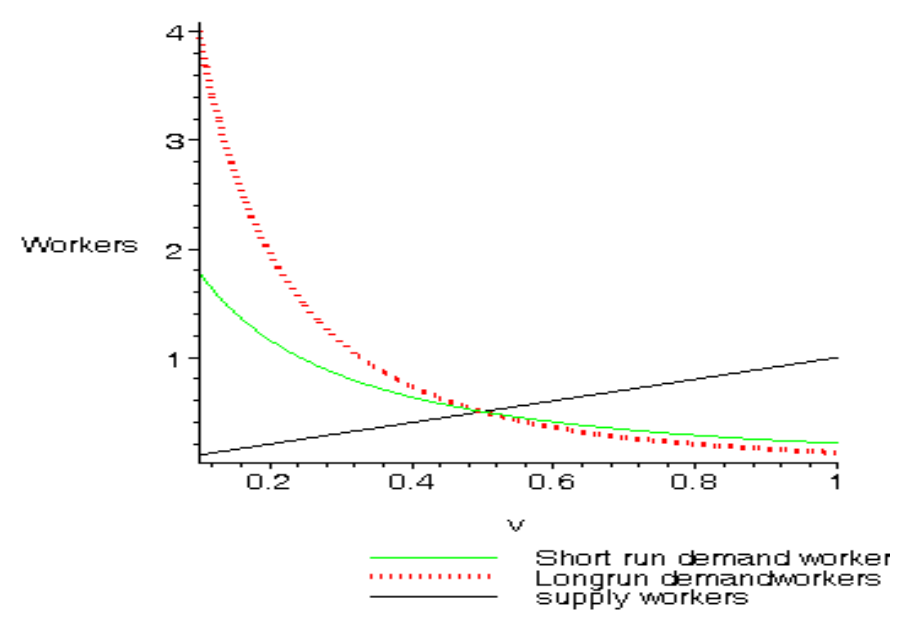

Figure 4: Minimum wage and short run market demand

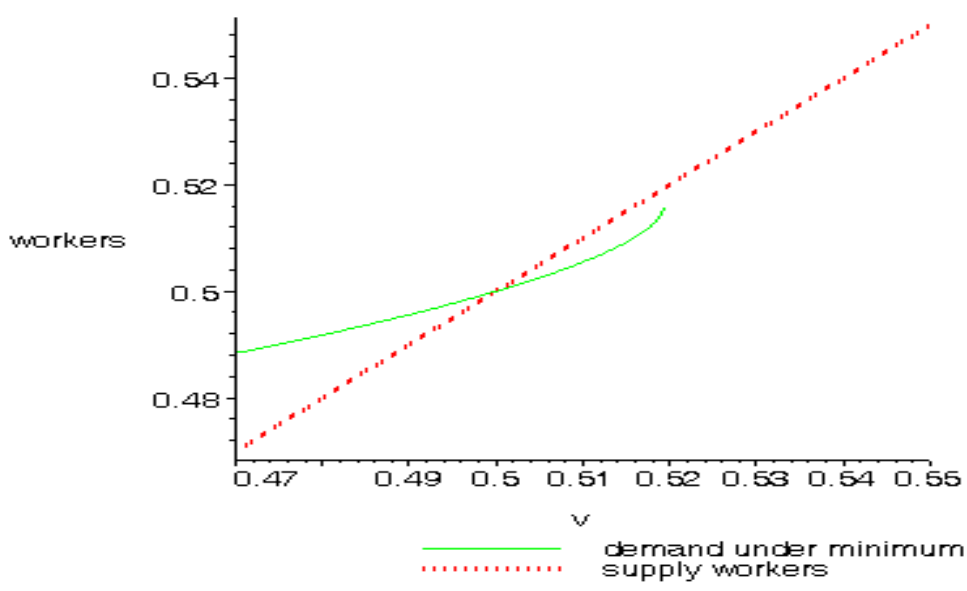


Figure 5: Minimum wage and total hours
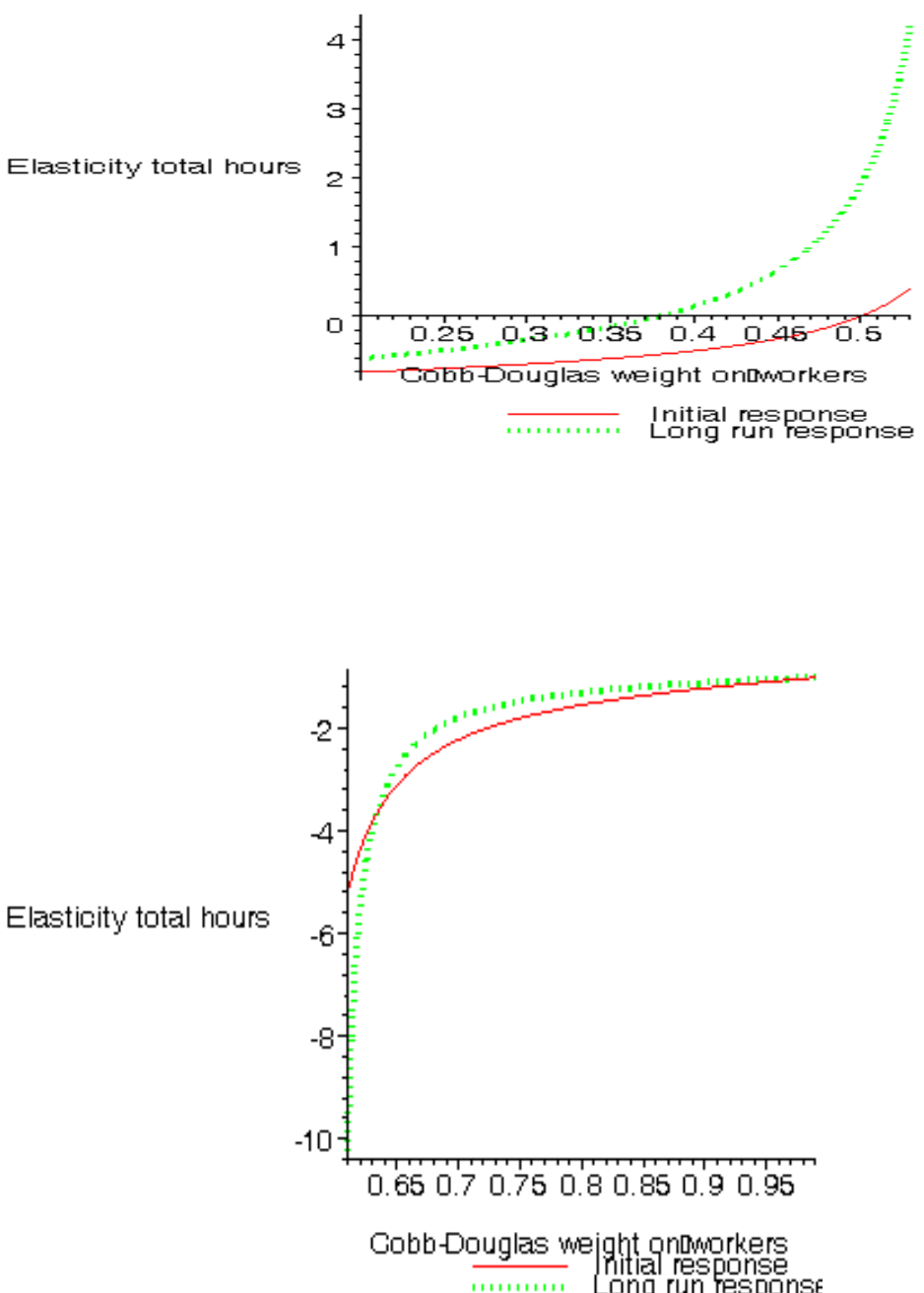
Table A1: Equilibrium values for the Cobb Douglas example

\begin{tabular}{|l|l|}
\hline Wage & Market wage: 4.031 \\
\hline $\begin{array}{l}\text { Output } \\
\left(y=h^{0.45} n^{0.55}\right)\end{array}$ & 0.55 \\
\hline $\begin{array}{l}\text { Utility } \\
u=w h(t-h)]\end{array}$ & 0.5 \\
\hline Profit $(\pi)$ & 0.96 \\
\hline $\begin{array}{l}\text { Hours per } \\
\text { worker (h) }\end{array}$ & 0.60 \\
\hline $\begin{array}{l}\text { Number of } \\
\text { workers (n) }\end{array}$ & 0.52 \\
\hline Wage & 2.08 \\
\hline
\end{tabular}

Simulated model from appendix 1. where $\mathrm{M}=\mathrm{p}=\mathrm{k}=\mathrm{t}=1$. The first column solves for values at the equilibrium market clearing wage. Since we assume a unit mass of workers are available we set the output price at 3.835 such that $\mathrm{u}=0.5$ and labour demand is less than labour supply.

\section{Appendix 1}

\section{Cobb-Douglas production and utility function}

In this section we illustrate our results using a Cobb-Douglas example. This example is used to generate the results in Table A1 above and Figures 1 through 3 . A maple file generating these simulations and graphs is available from the authors on request. The technology over hours and workers is $f(n, h)=h^{a} n^{b}$. A commonly used approach is to model the aggregate labour labour input as $H=n^{\eta} h^{\delta} \cdot{ }^{18}$ It also is important to remember that the technology above is for producing labour inputs and that one might expect that there is a diminishing marginal product associated with the labour input. One example would be $f(H)=H^{\beta}=n^{\eta \beta} h^{\delta \beta}=h^{a} n^{b 19}$ where both $a$ and $b$ are less than unity. Relative to $b$, a small value for $a$ means a worker intensive

\footnotetext{
${ }^{18}$ See Hamermesh (1993) for example.

${ }^{19}$ Another way of looking at it is that there are $s$ other inputs $x_{1} . . x_{s}$ in addition to labour $L$ and a CobbDouglas production function $f\left(x_{1}, \ldots x_{s}, H\right)=x_{1}^{\alpha_{1}} \ldots x_{s}^{\alpha_{s}} H^{b}$. The comparative static analysis would be much more complicated if we add more inputs, but the example shows that it would be plausible to have a production function where the weights on $h$ and $n$ would be less than unity.
} 
production function and a large value for $a$ implies an hours intensive production function. Of course this Cobb-Douglas example is a very simple special case, but the point is to show that even in this very simple but reasonable special case one can illustrate the possibility that the employment affects of minimum wages may be ambiguous when the weights on hours and workers differ. We note that in this case equation (1.4) becomes:

$$
\frac{d n}{d w}=\frac{\left[\frac{f_{h}}{n}-f_{n h}\right]}{f_{n n}} \frac{d h}{d w}=-\frac{a}{b} \frac{n}{h} \frac{d h}{d w}
$$

In the Cobb-Douglas case equation (1.3) holds by construction. Equation (1.6) becomes:

$$
\frac{d(n h)}{d w}=n \frac{d h}{d w}+h \frac{d n}{d w}=n\left[\frac{b-a}{b}\right] \frac{d h}{d w}
$$

To solve for equilibrium hours we continue by assuming that workers have the CobbDouglas utility function: $u=c l-v=w h(T-h)-v$. Workers have a reservation utility $k$ as described in Section III and $v$ is a fixed cost associated with going to work. At the equilibrium level of utility the indifference curve is:

$$
w=\frac{u}{h(t-h)}
$$

We assume the firm has a Cobb-Douglas production function $f(n, h)=h^{a} n^{b}$. For the moment we take the equilibrium value of $u$ as given. We will solve for labour market equilibrium in a simple example below. Given the utility function the slope of the wage hours locus is just the slope of the indifference curve of the marginal worker:

$$
\frac{d h}{d w}=\frac{[h(t-h)]^{2}}{(-t+2 h) u}
$$


It follows that if $t>2 h$ then $\frac{d h}{d w}<0$ and if $t<2 h$ then $\frac{d h}{d w}>0$. The representative firm's profit function is:

$$
\pi(n, h)=h^{a} n^{b}-\frac{n u}{(t-h)}-k n
$$

From the first order conditions on $n$ and $w$ we get the following quadratic form for $h$ :

$$
\left(u t+k t^{2}\right)-\left[\left(\frac{a+b}{a}\right) u+2 k t\right] h+k h^{2}=0
$$

Noting that $h<t$ the solution is:

$$
h=t+\left(\frac{a+b}{a}\right) \frac{u}{2 k}-\frac{\sqrt{(a+b)^{2} u^{2}+4 k t a b u}}{2 k a}
$$

Given these considerations the easiest way to proceed is to simulate the model. Table A1 above assumes parameter values and solves for equilibrium outcomes.

\section{Figures 1 and 2}

Using equation $\mathrm{A}(1.3)$ above we can trace out the indifference curve in Figure 1. for the assumed values for $u$ and $t$ given in Table A1. Taking the first order condition on $n$ we can rewrite $\mathrm{A}(1.5)$ in terms of the hourly wage $w$ and trace out the relationship between hours and the wage at the equilibrium level of profit. This is the isoprofit curve plotted in Figure 1.

Again from the profit maximising solution for $n$ and $h$ we can solve for the equilibrium cost of production $c$. Solving $c=w h n+n k$ for $\mathrm{h}$ and using $\mathrm{A}(1.3)$ for w. This gives the isocost curve in Figure 2. Using the solutions for $h$ and $n$ from profit maximisation we calculate the equilibrium value of output. Using this value we rearrange the production function in terms of $h$ and graphing this gives the isoquant in Figure 2. 


\section{Long run market equilibrium}

If we assume that $v$ has a uniform distribution over the unit interval and that reservation utility is normalised to zero then we get that $G(h, w)=v$ and also that labour supply is: $N^{s}=v M$. We assume a positive linear relationship between firm entry and profits $F=f \pi$ where we set f equal to unity. Labour demand is $N^{d}=n F=n f \pi$. Since profit depends on the output price level of $p$ for convenience we set this such that the equilibrium value of $\mathrm{v}^{*}=0.5$. We assume that the weight on workers $b$ equals one minus $a$ the weight on hours $b=1-a$. The long run elasticity of hours in Figure 3 uses the parameter values assumed in Table A1 except for the values of $a$ and $b$.

\section{Appendix 2}

Condition for scale effect on hours to be positive.

We minimise cost subject to the constraint that a given level of output $q$ is produced using the lagrangean $t$. The labour aggregator $f(h, n)$ turns combinations of workers $(n)$ and hours per worker $(h)$ into an amount $(q)$ of output. The equilibrium hourly wage hours worked locus is: $h(w)$. A fixed cost $k$ must be paid per worker hired.

$$
\imath=w h(w) n+n k+\lambda\{q-f[n, h(w]\}
$$

The first order conditions on $\mathrm{w}, n$ and $\lambda$ respectively are:

$$
\begin{aligned}
& l_{w}(n, w, \lambda)=w h_{w}(w) n+h(w) n-\lambda f_{h}[n, h(w)] h_{w}(w)=0 \\
& l_{n}(n, w, \lambda)=w h(w)+k-\lambda f_{n}[n, h(w)]=0 \\
& \iota_{\lambda}(n, w, \lambda)=q-f[n, h(w)]=0
\end{aligned}
$$


Totally differentiating the first order conditions with respect to $\mathrm{w}, n, \lambda$ and $q$ we get the following matrix system:

$$
\left(\begin{array}{lll}
l_{w w} & l_{w n} & \boldsymbol{l}_{w \lambda} \\
\boldsymbol{l}_{n w} & \boldsymbol{l}_{n n} & \boldsymbol{l}_{n \lambda} \\
\boldsymbol{l}_{\lambda w} & \boldsymbol{l}_{\lambda n} & \boldsymbol{l}_{\lambda \lambda}
\end{array}\right)\left(\begin{array}{l}
\frac{d w}{d q} \\
\frac{d n}{d q} \\
\frac{d \lambda}{d q}
\end{array}\right)=\left(\begin{array}{c}
0 \\
0 \\
-1
\end{array}\right)
$$

If we call the (3X3) matrix above $A$, we can use Cramer's rule and the assumption that the scale effect on hours is greater than or equal to zero $\left(\frac{\partial h}{\partial q} \geq 0\right)$ and say that:

$$
\begin{aligned}
& \frac{d h}{d q}=\frac{d h}{d w} \frac{d w}{d q}=\frac{\left|A_{1}\right|}{|A|}=\frac{\frac{d h}{d w}\left(l_{w \lambda} l_{n n}-l_{w n} l_{n \lambda}\right)}{|A|} \\
& =\frac{\lambda \frac{d h^{2}}{d w}\left[\left(\frac{f_{h}}{n}-f_{h n}\right) f_{n}+f_{h} f_{n n}\right]}{|A|} \geq 0
\end{aligned}
$$

Note that $\lambda>0$ ( since $\lambda$ is marginal cost this will be true). The second order conditions for cost minimisation $|\mathrm{A}|<0$,. Also of course: $f_{h}>0, f_{n}>0, f_{n n}<0$ and $\frac{d h^{2}}{d w}>0$. Thus the term in squared brackets in $\mathrm{A}(1.12)$ must be negative implying:

$$
\left(\frac{\frac{f_{h}}{n}-f_{h n}}{f_{n n}}\right) f_{n}+f_{h}>0
$$

This also implies:

$$
-\frac{f_{h}}{f_{n}} \leq \frac{\left(\frac{f_{h}}{n}-f_{h n}\right)}{f_{n n}}
$$

The two terms in this inequality will be equal when scale effects are zero. It is instructive to analyse the impact of a minimum wage on the cost minimisation 
problem. We totally differentiate the first order conditions on $n$ and $\lambda$ from $A(1.10)$ to get the following matrix system:

$$
\left(\begin{array}{ll}
l_{n n} & \iota_{n \lambda} \\
\iota_{\lambda n} & \iota_{\lambda \lambda}
\end{array}\right)\left(\begin{array}{l}
\frac{d n}{d w} \\
\frac{d \lambda}{d w}
\end{array}\right)=\left(\begin{array}{c}
-\iota_{n w} \\
\iota_{\lambda w}
\end{array}\right)
$$

Using Cramer's rule again we get:

$$
\begin{gathered}
\frac{d n}{d w}=\frac{l_{n \lambda} l_{\lambda w}}{l_{n \lambda}^{2}}=-\frac{f_{n} f_{h} h_{w}}{f_{n}^{2}} \\
\frac{d \lambda}{d w}=\frac{-l_{n n} l_{\lambda w}+l_{n w} l_{\lambda n}}{l_{n \lambda}^{2}}=\frac{\lambda\left[\left(\frac{f_{h}}{n}-f_{h n}\right) f_{n}+f_{h} f_{n n}\right]}{f_{n}^{2}} h_{w}
\end{gathered}
$$

We note that holding output fixed the change in the number of workers in response to a minimum wage has the opposite sign to the slope of the wage hours locus from $\mathrm{A}(1.16)$. From $\mathrm{A}(1.12 \mathrm{we}$ know that as long as hours per worker is not an inferior input then $\lambda\left[\left(\frac{f_{h}}{n}-f_{h n}\right) f_{n}+f_{h} f_{n n}\right] \leq 0$. Using this fact in $\mathrm{A}(1.17)$ we see that the change in marginal cost $(\lambda)$ from a minimum wage has the opposite sign as the wage hours locus.

\section{Appendix 4}

\section{Deriving Equation (1.5)}

From the first order condition on $h$ we can write:.

$$
h_{w}=\frac{h}{w}\left[\frac{1}{\left(\frac{p f_{h}}{w}\right)-1}\right]
$$

Also from the first order condition on $w$ we get: $w=\frac{p f_{n}-k}{h}$. Using this in $\mathrm{A}(1.14)$ we get: $\quad h_{w}=\frac{h}{w}\left[\frac{1}{\left(\frac{p f_{h} h}{p f_{n} n-k n}\right)-1}\right]$. Looking at the denominator of this equation we 
note: $\frac{p f_{h} h}{p f_{n} n-k n}=\frac{p f_{h} h}{p f_{n} n\left(1-\frac{k}{p f_{n}}\right)}$. Also $w h+k=p f_{n}$ from the first order condition w implying equation (1.5). 